\title{
Márcate un discurso con Cortázar
}

LORENA RIVERA LEÓN

Universitat de València

Lorena.Rivera@uv.es

\begin{abstract}
Resumen: Por su frecuencia de aparición y el papel que desempeñan en las inferencias pragmáticas, los marcadores del discurso resultan indispensables en la adquisición de la competencia comunicativa a la que debe aspirar todo estudiante de E/LE. Sin embargo, los docentes afrontan no pocas dificultades para trabajar con ellos, entre otras cosas porque son escasos y a menudo erráticos los materiales diseñados específicamente para enseñarlos. Con el propósito de paliar este déficit, presentamos una secuencia didáctica pensada para un nivel C1 y ensamblada como una aproximación coherente a la figura de Julio Cortázar. En el tratamiento de los marcadores discursivos adoptamos la perspectiva cognitivo-pragmática de autores como Martín Zorraquino y Portolés (1999) y Pons Bordería (2000) al mismo tiempo que seguimos las recomendaciones del MCER y el $P C I C$, subrayando expresamente la necesidad de que el alumno use estrategias de reflexión y toma de conciencia.
\end{abstract}

Palabras clave: Marcadores del discurso, pragmática, lingüística cognitiva, literatura hispanoamericana

\section{Discourse marking with Cortázar}

Abstract: Due to their frequency of use and the role they play in pragmatic inferences, discourse markers are essential for the acquisition of communicative competence in Spanish L2. However teachers are often in trouble when they work with these linguistic units, among other things, because didactic materials specifically designed to teach them are rare and often erratic. With the aim of palliating this shortage a didactic sequence has been designed. It is addressed to $\mathrm{C} 1$ level and assembled as a coherent approach to the figure of Julio Cortázar. The cognitive-pragmatic perspective of authors like Martín Zorraquino and Portolés (1999) and Pons Bordería (2000) is adopted in this material. Besides, suggestions provided by the Common European Framework of Reference for Languages (CEFR) and the PCIC are followed putting emphasis on the need of awareness and reflection strategies for students.

Keywords: Discourse markers, pragmatics, cognitive linguistics, Hispanic American literature

\section{Presupuestos teóricos y consideraciones metodológicas}

La altísima frecuencia de aparición de los marcadores del discurso en cualquier interacción revela que el dominio de estas unidades lingüísticas invariables es esencial para todo estudiante que aspire a ser comunicativamente competente en su uso del español. Sin embargo, diversos estudios (Zorraquino 2004; Corral, 2009, Nogueira da Silva, 2012, entre otros) apuntan a las dificultades que tanto los aprendientes como los profesores de E/LE tienen para abordarlos de forma específica. Tras analizar un corpus constituido por ocho manuales de E/LE de nivel C1, Nogueira da Silva (2012) concluye 
que aún queda mucho trabajo por hacer en este terreno. Con la propuesta que aquí se presenta, aspiramos a paliar, siquiera sea levemente, este déficit.

La secuencia didáctica está pensada para un nivel $\mathrm{C} 1$, y también podría usarse en un $\mathrm{C} 2$, pues es en los niveles más avanzados donde, de acuerdo con el Marco común europeo de referencia para las lenguas $(M C E R)$, se le exige al estudiante el dominio de estructuras organizativas, conectores y mecanismos de cohesión.

Para el diseño de las actividades hemos atendido al ya mencionado MCER así como al Plan curricular del Instituto Cervantes (PCIC) elaborado a partir de sus recomendaciones, adoptando así un enfoque orientado a la acción y centrado en el alumno. Frente a la tendencia de profesores y alumnos a recurrir a la traducción cuando de marcadores discursivos se trata (Corral 2009: 3), nuestra propuesta busca promover la toma de conciencia y una actitud reflexiva, aunque intentando, al mismo tiempo, limitar en la medida de lo posible las explicaciones metalingüísticas que siempre conllevan el riesgo de amedrentar al alumno no especialista. Puesto que nuestro enfoque es cognitivo, asumimos que el estudiante ha de participar de forma activa en su proceso de aprendizaje sirviéndose de distintas estrategias mentales que le ayuden a asimilar los nuevos contenidos en el sistema lingüístico que está aprendiendo.

En el tratamiento de los marcadores hemos adoptado la perspectiva cognitivo-pragmática de autores como Martín Zorraquino y Portolés (1999) y Pons Bordería (2000). Así, para configurar la secuencia hemos seguido la clasificación de los marcadores discursivos hecha por los primeros en la Gramática descriptiva de la lengua española, donde se da la siguiente definición del término:

Los «marcadores del discurso» son unidades lingüísticas invariables, no ejercen una función sintáctica en el marco de la predicación oracional -son, pues, elementos marginales- y poseen un cometido coincidente en el discurso: el de guiar, de acuerdo con sus distintas propiedades morfosintácticas, semánticas y pragmáticas, las inferencias que se realizan en la comunicación.

Zorraquino y Portolés (1999: 4057)

Otras obras de referencia han sido el Diccionario de partículas discursivas del español del equipo Val.Es.Co. (Briz 2008), así como los trabajos de Borrego Nieto (2013), Martín Zorraquino (2004) y Martínez Sánchez (2011).

Las actividades diseñadas se clasifican en tres grandes grupos: reconocimiento, focalización y puesta en práctica, aunque dentro del segundo grupo cabe distinguir ejercicios de distinto tipo. De manera esquemática, las actividades creadas quedarían distribuidas de la siguiente manera:

a) Actividades de reconocimiento, ligadas a la comprensión lectora: actividad 1, apartados $a, b, d$.

b) Actividades de focalización, en las que la atención se centra en el significado y uso textual de los marcadores del discurso:

- Ejercicios que persiguen determinar opciones vinculadas significativamente: actividad 1, apartado $c$.

- Ejercicios que intentan determinar opciones claramente diferentes desde el punto de vista significativo: actividad 2 . 
- Ejercicios que buscan que el estudiante sepa ordenar los miembros vinculados por el marcador y situar este en el miembro pertinente: actividad 5, apartados $a$ y $b$.

- Ejercicios que persiguen establecer variantes, a veces no solo estilísticas, de la misma idea: actividad 3, apartados $a$ y $b$.

- Ejercicios en los que el alumno ha de elegir entre un listado de marcadores de distinto tipo cuál es la opción adecuada en cada caso (texto con huecos): actividad 4.

c) Actividades de puesta en práctica, en las que se privilegia la composición textual: actividad 6.

La unidad didáctica está también concebida como una aproximación a la obra literaria de Julio Cortázar, lo cual la convierte en un importante contenido cultural. Los textos que forman parte de ella se han elegido con un doble criterio: por una parte, que fueran relevantes dentro de la producción literaria del escritor argentino o que al menos -es el caso de los textos periodísticos- sirvieran como un acercamiento de conjunto a su obra; por otra parte, que permitieran el trabajo con los marcadores que en cada caso nos interesaban. Hemos seleccionado dos tipos de texto: en primer lugar, fragmentos de narraciones del propio Cortázar; en segundo término, textos periodísticos escritos a propósito de la conmemoración del centenario de su nacimiento el 26 de agosto de 2014 o con motivo de la celebración de los cincuenta años de la publicación de Rayuela en 2013. A estos se han sumado textos creados ex profeso, bien para dar algún apunte cultural o contextual o bien pensados como ejercicios con los marcadores discursivos. Desde la primera a la última actividad se ha buscado que hubiera coherencia en la presentación de la obra de Cortázar, pudiendo distinguirse tres momentos: introducción general al autor (actividad 1); atención a los cuentos, con una actividad dedicada expresamente a "Casa tomada» (actividades 2 y 3); y trabajo sobre Rayuela (actividades 4, 5, y 6). En el apartado «Secuencia de actividades» de la Guía del profesor se ofrece información más detallada sobre las distintas actividades de la unidad didáctica.

\section{Guía del profesor}

\subsection{Nivel: $\mathrm{C} 1$}

\subsection{Destinatarios}

La secuencia didáctica está concebida para todo tipo de estudiantes del nivel indicado, razón por la cual se han simplificado al máximo las explicaciones metalingüísticas. Incluso alguna actividad podría utilizarse de manera separada en un nivel B2 cuando se introdujeran los marcadores en los que esté focalizada. Lo idóneo sería que los estudiantes que trabajaran con la unidad completa estuvieran ya bastante familiarizados con el uso de los marcadores del discurso, de modo que pudieran servirse de los cuadros gramaticales que se proporcionan a modo de simple recordatorio. Por otra parte, teniendo en cuenta que el hilo conductor de toda la secuencia es la obra literaria de Julio Cortázar, sería deseable que los alumnos tuvieran interés, o al menos curiosidad, por la narrativa hispanoamericana del boom de los años 60 del siglo pasado. 


\subsection{Objetivos}

El objetivo principal de la secuencia didáctica es facilitar la comprensión del funcionamiento de determinados marcadores discursivos a estudiantes de español de nivel $\mathrm{C} 1$ a fin de que los hagan suyos y los empleen de forma adecuada. Paralelamente, se pretende también familiarizarlos con un referente cultural fundamental como Julio Cortázar, ampliando así su conocimiento del mundo. No obstante, como este último es un objetivo subsidiario del principal, no se han explotado los textos buscando profundizar en la obra literaria de Cortázar. Aun así, el trabajo continuado con textos periodísticos y literarios complejos mejorará sin duda la comprensión escrita del alumnado, enriquecerá su vocabulario e incluso tendrá un impacto positivo en su expresión escrita.

\subsection{Destrezas lingüísticas implicadas}

Comprensión y expresión escrita.

\subsection{Material necesario}

El cuadernillo «Material del alumno» que se ofrece como anexo. Asimismo, se proporciona una Guía del profesor que incluye un solucionario.

\subsection{Secuencia de actividades}

La secuencia didáctica está integrada por las seis actividades que se detallan a continuación.

\section{Actividad 1: Julio Cortázar, all that jazz}

Es una actividad montada a partir de la adaptación de un artículo periodístico publicado en el diario El País el 26 de agosto de 2014 con motivo del centenario del nacimiento de Cortázar. Además de acortar el texto, se lo ha modificado con la inclusión de algunos marcadores del discurso que inicialmente no estaban en él.

La actividad, bastante extensa, consta de cinco apartados. Desde el punto de vista de la aproximación a la obra de Cortázar, la propuesta cumple con el objetivo de presentar al autor y de dar algunas pinceladas sobre su obra. El apartado $e$, con el cual se busca que los alumnos identifiquen los cuentos de Cortázar a los que se hace referencia en distintas partes del artículo, está pensado para enlazar con la actividad 2, en la que los estudiantes trabajarán con los marcadores discursivos a partir de seis fragmentos tomados de cada uno de los seis cuentos o libros de cuentos a los que se alude en el artículo periodístico.

En cuanto a la tarea con los marcadores del discurso, los apartados $a, b$ y $d$ constituyen actividades de reconocimiento. La dificultad de cada uno de estos apartados es creciente: en el $a$ simplemente se les pide a los estudiantes que ordenen un párrafo largo del texto y que indiquen qué estrategias han usado para hacerlo, con la previsión de que los marcadores del discurso les habrán servido de ayuda; en el $b$ han de clasificar en distintas categorías los marcadores discursivos del texto, que se les dan señalados en él; ya por último, en el apartado $d$ tienen que intentar describir el valor en el texto de diez marcadores seleccionados de entre los que aparecen en él. La circunstancia de que todos los marcadores estén contextualizados debería ayudarles a realizar el ejercicio. 
Por otra parte, con el apartado $c$ se pretende que se determinen opciones vinculadas significativamente. Para ello se han seleccionado diez marcadores del texto, pertenecientes a distintas categorías, que se han ordenado en una primera columna, mientras que en una segunda se ha recogido, para cada uno de los diez marcadores elegidos, uno de valor similar. Los estudiantes han de relacionar los marcadores de ambas columnas creando parejas de valores semejantes.

\section{Actividad 2: Márcate un cuento}

Desde el punto de vista secuencial, esta actividad enlaza directamente con el apartado $e$ de la anterior. Se han seleccionado seis fragmentos de los cuentos o libros de cuentos a los que se hacía referencia en el artículo de la actividad 1 y cuyos títulos ya conocen los alumnos. En cada uno de esos fragmentos hay un marcador que se ha eliminado, de modo que los estudiantes han de seleccionar, de entre cuatro opciones posibles, cuál es la adecuada. Se ha buscado que las cuatro alternativas pertenecieran a categorías diferentes, de modo que solo hubiera una solución válida en cada caso. Es, pues, un ejercicio que intenta determinar opciones claramente diferentes desde el punto de vista significativo.

Actividad 3: «Casa tomada», ese «simple y silencioso matrimonio de hermanos»

Esta actividad permite conocer «Casa tomada», uno de los cuentos más emblemáticos de Cortázar. En cuanto a los marcadores del discurso, se proponen dos ejercicios que persiguen establecer variantes, a veces no solo estilísticas, de la misma idea. En el apartado a se trabaja con los conectores aditivos incluso (misma escala) y además (distinta escala). Aunque en el solucionario se ofrecen oraciones completas, ha de tenerse en cuenta que estos dos conectores admiten movilidad, razón por la cual son posibles variantes en la oración que construya el alumno. En el apartado $b$ se estudia la diferencia entre los conectores consecutivos así que (monofónico) y entonces (polifónico).

\section{Actividad 4: Medio siglo de Rayuela}

Las actividades 4, 5 y 6 están centradas en Rayuela. El punto de partida es un texto creado a partir del artículo «Rayuela, ¿cursi o clásico?», publicado en El País el 28/06/2013, y del reportaje «Rayuela, sigue el juego», aparecido en el mismo periódico un día después, el 29/06/2013. De este texto se han eliminado los marcadores del discurso, de modo que los estudiantes han de colocarlos en la posición adecuada a partir de un listado. Como posible dificultad cabe mencionar que algunos de los marcadores discursivos eliminados tienen valores similares (en realidad y de hecho; sin duda y desde luego; en cambio y sin embargo), por lo cual en ciertos casos puede haber más de una solución factible.

\section{Actividad 5: La Maga y Oliveira}

Se presentan aquí dos ejercicios en los que se busca que el estudiante sepa ordenar los miembros vinculados por el marcador dado y situar este en el miembro pertinente. En los apartados $a$ y $b$ se trabaja, respectivamente, con los conectores contraargumentativos eso sí y antes bien.

\section{Actividad 6: Una rayuela de cuento}

La última actividad didáctica es de puesta en práctica. Manteniendo el propósito de aunar la enseñanza de los marcadores del discurso con la aproximación a la obra de Cortázar, proponemos que los alumnos creen un pequeño cuento de entre 300 y 500 palabras en el que tendrán que servirse de al menos cuatro marcadores del discurso. Distribuidas en las ocho casillas de una rayuela, se ofrecen las primeras palabras de cada uno de los ocho 
párrafos que componen el cuento «Simulacros», contenido en Historias de cronopios y de famas. Recurriendo a un mínimo de cuatro de las casillas, los estudiantes tendrán, a modo de juego, que componer su cuento.

\subsection{Duración aproximada}

La duración global de la unidad didáctica dependerá en gran medida de las características del grupo meta y ello no solo porque el grado de dominio de los marcadores del discurso pueda ser variable dentro de un mismo nivel $\mathrm{C} 1$, sino también porque la circunstancia de que el eje temático de la secuencia de actividades sea la obra de Julio Cortázar puede dar lugar a que surjan entre el alumnado intereses e inquietudes más allá del plano de los marcadores discursivos, que el profesor tendrá que saber gestionar de acuerdo con el tiempo de que disponga. En cualquier caso, se ofrecen los siguientes tiempos a modo de referencia:

- Actividad 1: Julio Cortázar, all that jazz: 50-60 minutos.

- Actividad 2: Márcate un cuento: 25 minutos.

- Actividad 3: «Casa tomada», ese «simple y silencioso matrimonio de hermanos»: 20-25 minutos.

- Actividad 4: Medio siglo de Rayuela: 30-40 minutos.

- Actividad 5: La Maga y Oliveira: 20 minutos.

- Actividad 6: Una rayuela de cuento: Presentación en clase (5 minutos); desarrollo por parte del alumno (posiblemente como tarea para casa): 60 minutos.

\subsection{Solucionario}

\section{Actividad 1: Julio Cortázar, all that jazz}

Apartado $a$ : En el apartado $b$ de la misma actividad aparece ordenado el texto.

Apartado $b$ :

- Estructuradores de la información (comentadores): así las cosas.

- Estructuradores de la información (ordenadores): en primer lugar, en fin.

- Conectores aditivos: además.

- Conectores contraargumentativos: sin embargo, ahora bien, en cambio.

- Reformuladores de distanciamiento: en cualquier caso.

- Operadores argumentativos (de refuerzo argumentativo): en realidad.

- Operadores argumentativos (de concreción): por ejemplo, en particular.

- Marcadores conversacionales de evidencia: en efecto, claro, sin duda, desde luego, por supuesto, naturalmente, efectivamente.

Apartado $c$ : 1d, 2a, 3b, 4j, 5c, 6f, 7i, 8e, 9h, 10g.

sin embargo

además

ahora bien

en cualquier caso

en cambio

por supuesto

en realidad no obstante

encima

eso sí

de todos modos

por el contrario

desde luego

de hecho 


$\begin{array}{ll}\text { en primer lugar } & \text { primeramente } \\ \text { en fin } & \text { en último término } \\ \text { efectivamente } & \text { claro }\end{array}$

Apartado $d$ :

MARCADOR DISCURSIVO

Sin embargo

Además

Ahora bien

En cualquier caso

En cambio

Por supuesto

En realidad

En primer lugar

En fin

Efectivamente

\section{VALOR EN EL TEXTO}

Refuta lo presentado previamente.

Añade una nueva idea o argumento.

Introduce un nuevo miembro que elimina alguna conclusión que se pudiera derivar del discurso anterior.

Ante distintas posibilidades o casos previos, indica que, cualquiera que sea la elección, se mantiene como conclusión el miembro que él introduce.

Muestra un contraste entre los dos miembros discursivos que relaciona.

Expresa evidencia.

Presenta el argumento que se introduce con la fuerza que le da su realidad o existencia, frente a la apariencia o probabilidad de otro argumento.

Sirve para abrir una serie en el discurso.

Marca el cierre de una secuencia discursiva.

Destaca lo evidente del discurso emitido.

Apartado $e$ : 1e, 2b, 3c, 4a, 5d, $6 \mathrm{f}$

\section{Actividad 2: Márcate un cuento}

Además de ofrecer la solución, se especifica aquí qué tipo de marcador del discurso es cada una de las opciones correctas:

- 1b: Además es un conector aditivo.

- 2c: Con todo es un conector contraargumentativo.

- 3d: En realidad es un operador de refuerzo argumentativo.

- 4a: En cambio es un conector contraargumentativo.

- 5b: Primero pertenece a la categoría de los estructuradores de la información, dentro de la cual es un ordenador de apertura.

- 6d: Sin embargo es un conector contraargumentativo.

\section{Actividad 3: Casa tomada, ese «simple y silencioso matrimonio de hermanos»}

Apartado $a$ :

1. Es una casa sin demasiada decoración, incluso austera. 
2. Tiene muchas habitaciones y algunas, además, están vacías.

3. Está muy limpia, incluso resplandeciente.

4. Tiene una cocina amplísima y además bien amueblada.

5. Es una casa tranquila, incluso silenciosa.

6. Es una casa heredada y además está en el centro de Buenos Aires.

7. Es una casa agradable, incluso acogedora.

8. Tiene amplios ventanales y además muebles preciosos.

Apartado $b$ :

1. Dices que quieres acabar de tejer el suéter antes de acostarte. Entonces, empieza ya.

2. He oído ruidos, así que nos quedaremos de esta parte de la casa.

3. Dices que ya has acabado de leer el libro. Entonces, prepara la cena.

4. Dices que ya no tienes más lana. Entonces, tendrás que dejar de tejer.

5. Dices que ya no queda más por limpiar. Entonces, descansemos.

6. Salí corriendo, así que tengo solo lo puesto.

7. Se me quedó la lana del otro lado, así que ya no podré tejer más.

8. Un ladrón puede querer entrar en la casa, así que tiraré la llave por la alcantarilla.

\section{Actividad 4: Medio siglo de Rayuela}

Listado de marcadores según su orden en el texto: sin duda, por ejemplo, desde luego, en cambio, a fin de cuentas, pues, sin embargo, en realidad, más aún, en cambio, de hecho, en fin, eso sí.

Texto completo con los marcadores destacados:

«¿Encontraría a la Maga...?» Sin duda, de los libros inolvidables uno aprende de memoria al menos el primer párrafo, o esa lectura nunca existió, se la llevó el agua del tiempo en su fluir incesante. Y la entrada de Rayuela puede leerse ya, pasado medio siglo, como la de cualquier otro de los clásicos que vuelven siempre a la memoria envueltos en su propio resplandor como sucede, por ejemplo, con el arranque de Anna Karénina, La metamorfosis o Cien años de soledad.

Para los nostálgicos que aprendimos en las páginas de Rayuela a despreciar el orden establecido y a cuidarnos de la transgresión de escribir en papel rayado y apretar el tubo de pasta dentífrica desde abajo, cabe una pregunta: ¿habrá envejecido Rayuela junto con todos nosotros? Es una pregunta generacional y hay que tomarla desde luego así.

He indagado entre los escritores jóvenes que se abren camino en este siglo XXI de tan pocas certezas y demasiadas incertidumbres, si reconocen en ella su atrevido sentido de ruptura, la narración siempre al borde del abismo, al lector que atraviesa la cuerda floja en persecución del novelista que va por delante balanceando la pértiga en busca de una alternancia perturbadora entre lo cómico y lo trágico.

Algunos coinciden plenamente conmigo, otros, en cambio, me han dicho que lo que pasa es que Rayuela fue a mi generación lo que Los detectives salvajes de Bolaño es a las nuevas, una Biblia laica de enseñanzas acerca de cómo romper todos los platos de la alacena con el mayor escándalo posible, pero a fin de cuentas se trata de dos generaciones distintas. Veamos, pues, qué opinan los más jóvenes.

Un juguete sofisticado. A Agustín Fernández Mallo (A Coruña, 1967) le faltaban cuatro años para nacer cuando se publicó Rayuela. No la ha vuelto a leer entera desde la primera vez. Sin embargo, de cuando en cuando hace «catas selectivas». Su conclusión es que funciona muy bien a trozos, que tienen una entidad poética al margen de la narrativa. En su opinión, la novela de Julio Cortázar «abrió una vía al experimentalismo y al uso de la cultura popular sin tapujos, sin esa condescendencia que se usa para quedar bien. En Cortázar era algo vivido, real, no un artefacto montado ad hoc. Su influencia la admite la mayoría de los escritores españoles de mi generación». 
Mercedes Cebrián (Madrid, 1971) tampoco la ha vuelto a leer desde que lo hizo a los 17 años, y por eso insiste en que, en realidad, sus comentarios se refieren a aquella primera impresión. Ahora, dice, está curada de espanto, «vieja» (¿?), no querría parecer naïve. ¿Y a los 17? «Rayuela es una novela de formación esencial para un escritor en lengua castellana. Aprendes de todo, carpintería, bricolaje. Enseña también que la literatura no es solo seriedad, que puede ser un juego, que en una novela cabe lo que tú quieras. Me da pena pensar que ya no la podría releer con la ilusión del descubrimiento. También es un juguete sofisticado muy útil para bajarles los humos a los descubridores permanentes de artefactos que piensan que lo último de lo último es decirle a alguien, en la página 10 , "pase a la página 48 "».

Contra Rayuela. Desde la Argentina, Damián Tabarovsky (Buenos Aires, 1967) rompe contundentemente la devoción cortaziana: «¿En qué momento Rayuela se convirtió en un libro leído en la adolescencia y nunca jamás en la adultez? O más aún, ¿en qué momento pasó a ser un texto adolescente? No lo sé. Sé, en cambio, que para mí, y para muchos de mi generación, Cortázar significa esa época de la vida en que nos pasan cosas vergonzantes: decir que nos gustaba Cortázar es una de esas. De hecho, a mí nunca me pasó, pero sí me ocurrió con Roberto Fontanarrosa, que vendría a ser lo mismo, pero peor».

En 1962, en una carta, Julio Cortázar escribió: «Nadie es clásico si no quiere. Los profesores pueden pegarle la etiqueta, pero él (y sus libros) le escupen encima. Yo soy siempre el mismo desconcertado cronopio que anda mirando las babas del diablo en el aire, y que recién a los veinte mil kilómetros descubre que no ha soltado el freno de mano».

Cortázar, en fin, nunca envejeció, ni tampoco dejó de crecer, como no ha dejado de crecer Rayuela, un libro de iniciación que, igual que su autor, seguirá botando años por el camino. Solo hay que leerlo, o volver a leerlo empezando, eso sí, por el primer capítulo. Allí comienza su eternidad.

Texto adaptado a partir del artículo «Rayuela, ¿cursi o clásico?», publicado en El País el 28/06/2013, y del reportaje «Rayuela, sigue el juego» aparecido en el mismo diario el 29/06/2013.

\section{Actividad 5: La Maga y Oliveira}

Apartado $a$ : 1a, 2b, 3a

1. Horacio Oliveira no suele expresar abiertamente sus sentimientos, eso sí, ama a la Maga.

2. Horacio Oliveira vive en un apartamento húmedo e insalubre, eso sí, en París.

3. Horacio Oliveira sabía que el bebé de la Maga estaba muerto, eso sí, no se lo dijo a su madre.

Apartado $b$ : 1f, 2g, 2b, 4c, 5d, 6a, 7e.

1. La Maga no es rica, antes bien, es pobre.

2. La Maga no es muy espabilada, antes bien, es bastante ingenua.

3. La Maga no es culta, antes bien, apenas ha estudiado.

4. La Maga no es poco agraciada, antes bien, es muy atractiva.

5. La Maga no tiene don de palabra, antes bien, a veces le cuesta expresarse.

6. La Maga no es arisca, antes bien, es muy cariñosa.

7. La Maga no es observadora, antes bien, es bastante distraída.

\section{Bibliografía}

BorRego NieTO, Julio (dir.) (2013). Gramática de referencia para la enseñanza de español. La combinación de oraciones. Salamanca: Ediciones Universidad de Salamanca.

BRIZ, Antonio, S. Pons y J. Portolés (coords.) (2008). Diccionario de partículas del español. Proyecto del Grupo de investigación Val.Es.Co. En línea: www.dpde.es 
CORRAL ESTEVE, Cristina (2009). «Algunas propuestas para llevar los marcadores discursivos al aula de ELE». Suplementos MarcoELE, 9.

HERnÁndeZ, Jorge F. (2014/08/26). «Me espera Cortázar». El País.

MARTín Zorraquino, María Antonia y J. Portolés (1999). «Los marcadores del discurso». En I. Bosque y V. Demonte (eds.); Gramática descriptiva de la lengua española, 3 vols. Madrid: Espasa-Calpe, vol. 3, 4051-4214.

MARTín ZorRaquinO, María Antonia (2004). «El tratamiento lexicográfico de los marcadores del discurso y la enseñanza de E/LE». Actas del XV Congreso Internacional de ASELE.

MARTÍNEZ SÁNCHEZ, Roser (2011). Conectores textuales argumentativos: Guía y actividades didácticas para su uso eficaz en ELE. Barcelona: Octaedro.

NogueIRA DA SiLVA, A. Messias (2012). «Los marcadores del discurso y su introducción en los manuales de E/LE». Philologica Urcitana. Revista semestral de iniciación a la investigación en Filología, 7, 75-95.

Pons BorderíA, Salvador (2000). «Los conectores». En A. Briz y Grupo Val.Es.Co. (eds.); ¿Cómo se comenta un texto coloquial?(pp. 193-220). Barcelona: Ariel.

RAMíreZ, Sergio (2013/06/29). «Rayuela, sigue el juego». El País.

RoDRÍGUEZ MARCOS, Javier (2013/06/28). «Rayuela, ¿cursi o clásico?». El País.

VV.AA. (2002). Marco común europeo de referencia para las lenguas: aprendizaje, enseñanza, evaluación, (MCER), trad. cast. Madrid: MECD/Anaya.

VV.AA. (2006). Plan curricular del Instituto Cervantes. Niveles de referencia para el español, 3 vols. Madrid: Biblioteca Nueva. 


\section{ANEXO: MATERIAL DEL ALUMNO}

\section{En esta unidad vamos a...}

descubrir que hay pequeñas palabras sin las cuales seríamos desordenados e incoherentes: marcadores del discurso se llaman.

\section{En nuestro viaje...}

nos guiará un gigante de las letras hispánicas con mucho swing: Julio Cortázar.

\section{En su compañía...}

encontraremos personajes maravillosos: Horacio Oliveira y la Maga; la señorita Julia; Irene y su hermano, etc.
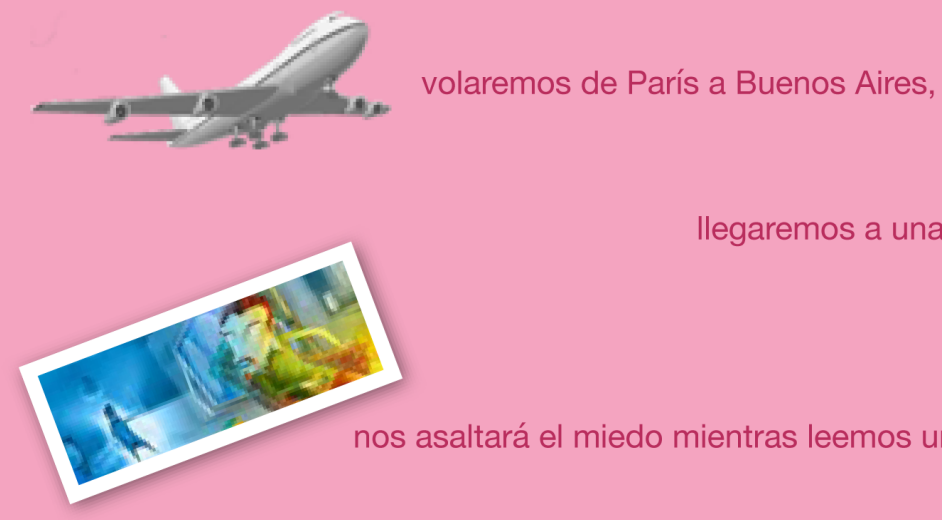

llegaremos a una casa tomada,

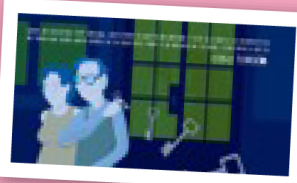

y hasta nos quedaremos atascados en una autopista hacia el sur,

pero terminaremos jugando a la rayuela.

\section{Nuestro plan es:}
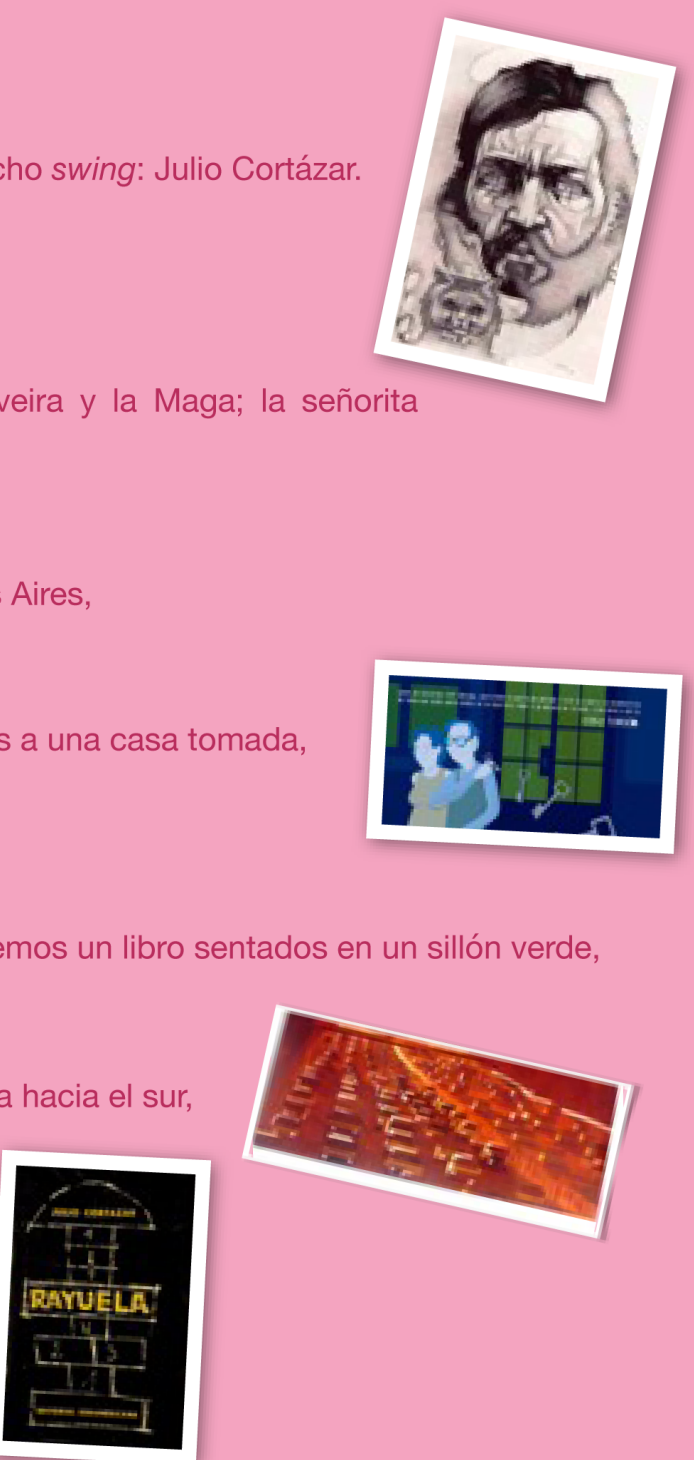

nos asaltará el miedo mientras leemos un libro sentados en un sillón verde,

Actividad 1: Julio Cortázar, all that jazz

Actividad 2: Márcate un cuento

Actividad 3: «Casa tomada», ese «simple y silencioso matrimonio de hermanos»

Actividad 4: Medio siglo de Rayuela

Actividad 5: La Maga y Oliveira

Actividad 6: Una rayuela de cuento 


\section{Actividad 1:}

\section{Julio Cortázar, all that jazz}

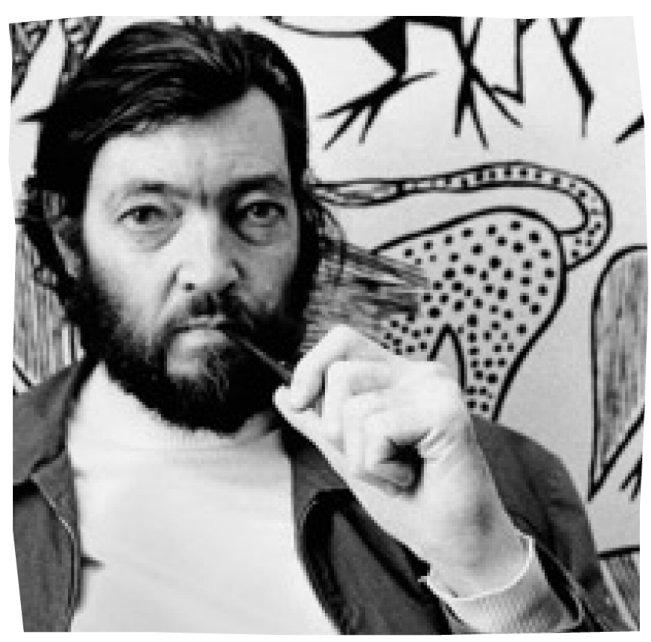

Julio Cortázar, uno de los grandes autores de la literatura en español del siglo XX, habría cumplido cien años en 2014. Ese mismo año se conmemoró también el $30^{\circ}$ aniversario de su muerte, acaecida en París el 12 de febrero de 1984." El escritor, nacido en Ixelles (Bruselas), el 26 de agosto de 1914, creció en Argentina hasta trasladarse a París en 1952. Fue una de las figuras destacadas del «boom» latinoamericano del siglo pasado, aunque se encuentra alejado de la línea realista y telúrica más tradicional de la narrativa hispanoamericana. Cultivó de manera magistral el cuento fantástico, indagando en el lado inquietante y perturbador de lo cotidiano. Gran subversor de los géneros, Rayuela, considerada por algunos su obra más sobresaliente, fue su arriesgada apuesta en el ámbito de la novela.

a) En 2014 se celebró el centenario del nacimiento de Julio Cortázar, apareciendo muchas semblanzas al respecto. A continuación, te presentamos un texto extraído de uno de esos retratos biográficos. Sin embargo, el último párrafo, bastante largo, está desordenado. Intenta ordenarlo de manera que el texto tenga sentido e indica qué estrategias has seguido para hacerlo. ¿Hay algún elemento que te haya ayudado especialmente a enlazar las partes?

\section{Me espera Cortázar}

La vida se vive mejor leída, leyéndola que es gerundio, leyendo a un escritor tan cercano que en realidad no se ha ido

El joven que cumple hoy un siglo estaba oteando la mesa de novedades en la vieja librería El Parnaso de Coyoacán. Yo tenía veinte años y, sin embargo, me sentí anciano por los nervios con los que enredé la lengua al acercarme a su altísima figura y balbucear la estúpida pregunta ¿Usted es Julio Cortázar? Así las cosas, el gigante se encogió de hombros con una sonrisa con la que disculpaba la obviedad, transpirando una confianza que combinaba con su aspecto

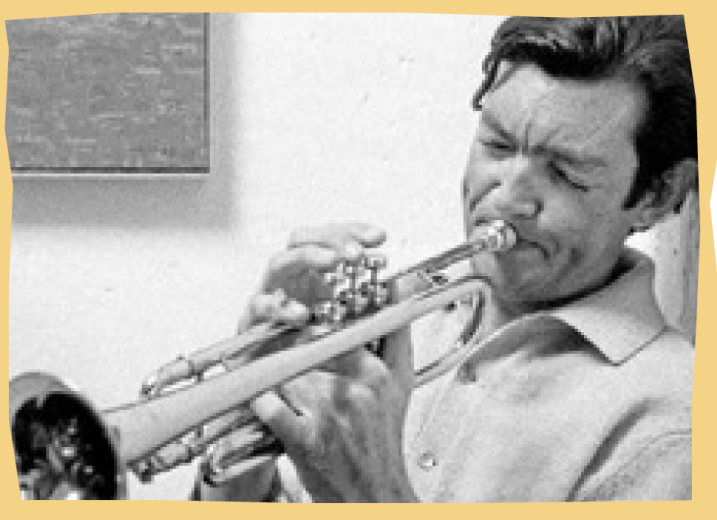


intemporal. Creo que le hizo gracia que le confesara que no traía lana en ese momento para comprarme otro ejemplar de Rayuela, que además lo tenía en casa y que iría corriendo por mi libro, que además tenía mis subrayados. Salí corriendo y regresé, en efecto, con el libro. Ahora bien, la cara irónica del dependiente de la librería me devolvió de inmediato a la realidad. ¿De veras creías que te iba a esperar?, me espetó con sorna. Y es que, claro, había gastado más de una hora en mi ilusionada travesía.

En cualquier caso, Cortázar cumple hoy un siglo y la cronometría de cronopio sin duda le permitirá cada cien años aparentar la juventud que llevaba en su cabellera larga, las barbas de trompetista trasnochado, la cara joven del que fuma un cigarrillo sin filtro, gabardina cinematográfica y toda la vida por delante en un puente de París en blanco y negro. Desde luego, no parece tener la misma edad que cumplen este año Octavio Paz o Adolfo Bioy Casares, que parecen haberse congelado de traje y corbata. En cambio, Cortázar parece andar hoy en medio de un sótano ritual del jazz sin hora de cierre y sus párrafos acompañan su lectura con la voz intacta.

Se equivoca quien crea que el jazz es pura improvisación (y si no, pregúntenle a Juan Sebastián Bach que lo inventó hace ya tantos siglos). De eso, por supuesto, sabía Cortázar en cada uno de sus medidos cuentos donde nos confirmó, por ejemplo, que hay señoritas en París capaces de provocar un raro sortilegio por el que cualquiera puede de pronto escupir pequeños conejitos por la boca. Nos aseguró, en particular, que hay madres que nos siguen escribiendo cartas con las últimas novedades de todo lo que pasa en casa, entregadas puntualmente en el buzón del departamento que hemos alquilado en un país lejano, sin importar que mamá en realidad ya murió. Naturalmente, esa magia, all that jazz, no se improvisa sino que se transpira y Julio Cortázar la sudaba en cada renglón que escribió, tanto en la enrevesada trama de su novela que se lee como quien juega a la rayuela o se come de un tirón con otra lógica comprensible, como en cada trama de sus cuentos donde los personajes son el lector que lee los párrafos donde él mismo se aproxima al sillón de terciopelo verde donde las palabras son el espejo de un hombre que se aproxima al sillón de terciopelo verde para cumplir una venganza perfecta.

1. De ese jazz sabían quienes lo leían y, desde luego, quienes lo conocieron de cerca o de lejos en el insólito espectáculo de un hombre que no parecía envejecer nunca, como si se quedara a vivir al volante de un automóvil anclado en medio de un embotellamiento infinito en una carretera.

2. De todo ese jazz supo, en primer lugar, Jorge Luis Borges cuando, en 1947, como secretario de redacción de una revista ya olvidada recibió de manos de «un muchacho muy alto» un cuento escrito a máquina de escribir con sus dedos alargados.

3. Dos metros de estatura inalcanzable, un ojo al gato y otro al garabato, la barba de hippie, las manos más largas del mundo, el cigarro sin filtro equilibrándose en los labios que sonríen y una gabardina que esconde como baúl sin fondo todas las tramas posibles de una novela que se multiplica como saxofón enloquecido y todos los personajes que se desdoblan en cuentos sin cuenta. Miro al estante y -efectivamente —me está esperando Julio Cortázar. 
4. Por supuesto, Borges no dudó en enviar directamente a la imprenta ése que sería el primer texto suyo que vería publicado Cortázar y que se inmortalizó en la lectura de todos con el título envidiable de «Casa tomada».

5. De ese jazz sabemos, en fin, quienes apreciamos la delicada minuciosidad con la que tradujo a grandes autores de idiomas que jamás imaginamos aprender y estimamos las cartas personales o los cursos de literatura que son ahora libros complementarios a su obra narrativa; clases y cartas para confirmar, en último término, que la vida se vive mejor leída, leyéndola que es gerundio, leyendo a un escritor tan cercano que en realidad no se ha ido: allí sigue, oteando siempre la mesa de novedades de la librería donde me cito de vez en cuando, sin citarme, con la Maga.

b) He aquí el texto completo donde podrás comprobar si has atinado en el ejercicio anterior. Verás que en él aparecen destacados en negrita dieciocho marcadores del discurso distintos, aunque tres de ellos (además, por supuesto y desde luego) se repiten dos veces. Clasifica todos los marcadores en las categorías adecuadas dentro del siguiente cuadro:

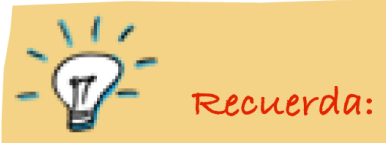

Los marcadores del discurso permiten que dotemos de coherencia a nuestro discurso y nos ayudan a ordenar las ideas.

Un marcador del discurso ha de reunir estas tres características:

$\Rightarrow \quad$ Es una unidad lingüística invariable, es decir, no admite, por ejemplo, el plural.

- No cumple ninguna función sintáctica en el marco de la predicación oracional como sí lo hacen los sustantivos, verbos, adjetivos, etc.

$\Rightarrow \quad$ Posee información procedimental, esto es, nos indica cómo hay que combinar la información.

Los marcadores del discurso suelen clasificarse en cinco grupos, cada uno de los cuales se divide a su vez en categorías subsiguientes:

- Estructuradores de la información (comentadores, ordenadores, digresores)

$\Rightarrow$ Conectores (aditivos, consecutivos, contraargumentativos)

- Reformuladores (explicativos, rectificativos, de distanciamiento, recapitulativos)

- Operadores argumentativos (de refuerzo argumentativo, de concreción)

- Marcadores conversacionales (de modalidad epistémica, de modalidad deóntica, enfocadores de la alteridad, metadiscursivos conversacionales) 

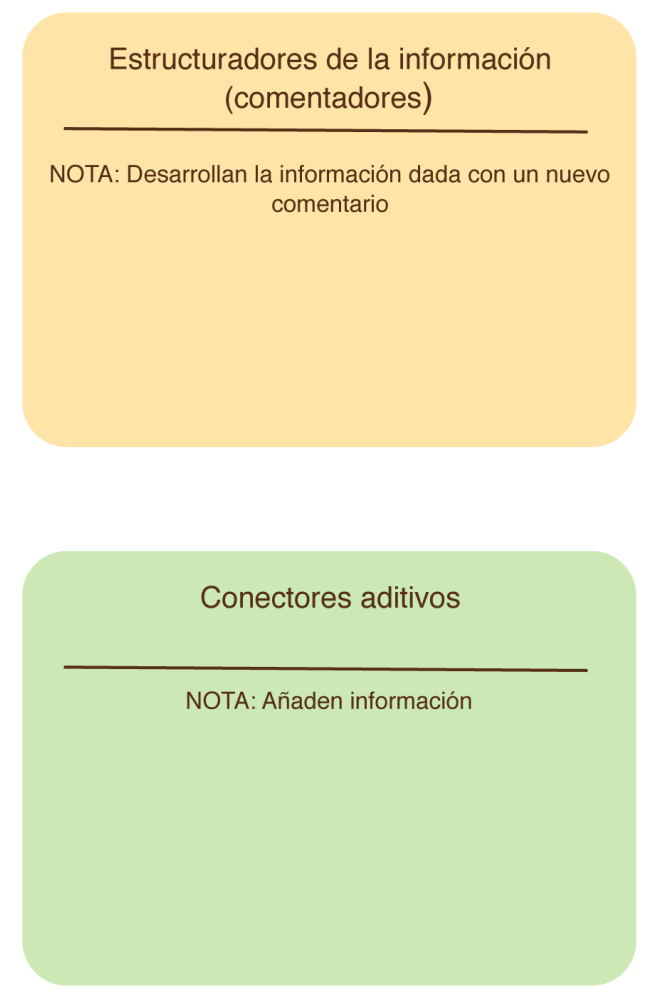

Reformuladores de distanciamiento

NOTA: Introducen una nueva información que le quita relevancia a lo dicho anteriormente

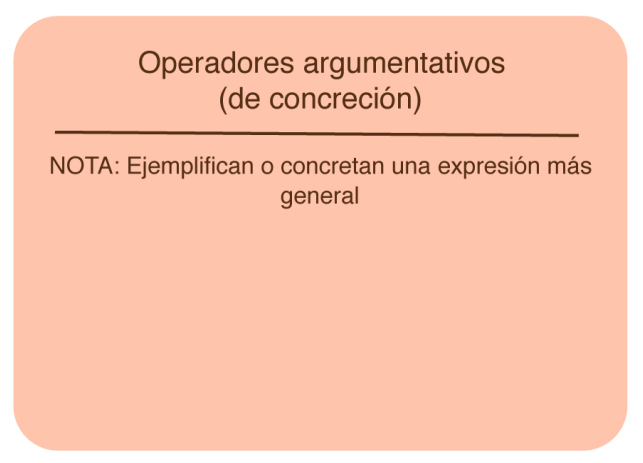

Estructuradores de la información (ordenadores)

NOTA: Ordenan la información

\section{Conectores contraargumentativos}

NOTA: Rectifican o refutan la información previamente dada

\section{Operadores argumentativos} (de refuerzo argumentativo)

NOTA: Refuerzan el argumento que presentan

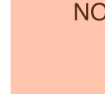

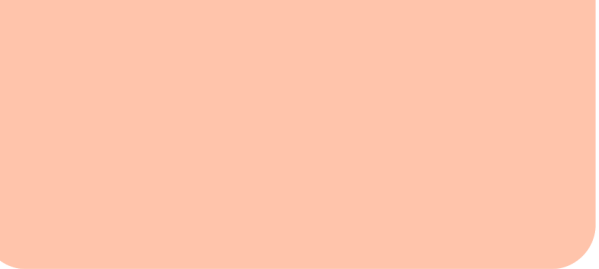

\section{Marcadores conversacionales de evidencia}

NOTA: Refuerzan una aseveración 


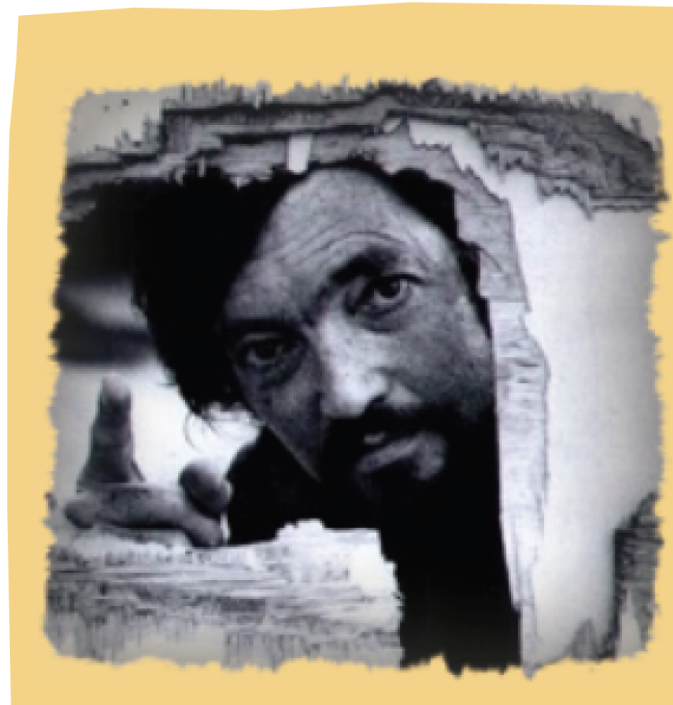

El joven que cumple hoy un siglo estaba oteando la mesa de novedades en la vieja librería El Parnaso de Coyoacán. Yo tenía veinte años y, sin embargo, me sentí anciano por los nervios con los que enredé la lengua al acercarme a su altísima figura y balbucear la estúpida pregunta ¿Usted es Julio Cortázar? Así las cosas, el gigante se encogió de hombros con una sonrisa con la que disculpaba la obviedad, transpirando una confianza que combinaba con su aspecto intemporal. Creo que le hizo gracia que le confesara que no traía lana en ese momento para comprarme otro ejemplar de Rayuela, que además lo tenía en casa y que iría corriendo por mi libro, que además tenía mis subrayados. Salí corriendo y regresé, en efecto, con el libro. Ahora bien, la cara irónica del dependiente de la librería me devolvió de inmediato a la realidad. ¿De veras creías que te iba a esperar?, me espetó con sorna. Y es que, claro, había gastado más de una hora en mi ilusionada travesía.

En cualquier caso, Cortázar cumple hoy un siglo y la cronometría de cronopio sin duda le permitirá cada cien años aparentar la juventud que llevaba en su cabellera larga, las barbas de trompetista trasnochado, la cara joven del que fuma un cigarrillo sin filtro, gabardina cinematográfica y toda la vida por delante en un puente de París en blanco y negro. Desde luego, no parece tener la misma edad que cumplen este año Octavio Paz o Adolfo Bioy Casares, que parecen haberse congelado de traje y corbata. En cambio, Cortázar parece andar hoy en medio de un sótano ritual del jazz sin hora de cierre y sus párrafos acompañan su lectura con la voz intacta.

Se equivoca quien crea que el jazz es pura improvisación (y si no, pregúntenle a Juan Sebastián Bach que lo inventó hace ya tantos siglos). De eso, por supuesto, sabía Cortázar en cada uno de sus medidos cuentos donde nos confirmó, por ejemplo, que hay señoritas en París capaces de provocar un raro sortilegio por el que cualquiera puede de pronto escupir pequeños conejitos por la boca. Nos aseguró, en particular, que hay madres que nos siguen escribiendo cartas con las últimas novedades de todo lo que pasa en casa, entregadas puntualmente en el buzón del departamento que hemos alquilado en un país lejano, sin importar que mamá en realidad ya murió. Naturalmente, esa magia, all that jazz, no se improvisa sino que se transpira y Julio Cortázar la sudaba en cada renglón que escribió, tanto en la enrevesada trama de su novela que se lee como quien juega a la rayuela o se come de un tirón con otra lógica comprensible, como en cada trama de sus cuentos donde los personajes son el lector que lee los párrafos donde él mismo se aproxima al sillón de terciopelo verde donde las palabras son el espejo de un hombre que se aproxima al sillón de terciopelo verde para cumplir una venganza perfecta. 
De todo ese jazz supo, en primer lugar, Jorge Luis Borges cuando, en 1947, como secretario de redacción de una revista ya olvidada recibió de manos de «un muchacho muy alto» un cuento escrito a máquina de escribir con sus dedos alargados. Por supuesto, Borges no dudó en enviar directamente a la imprenta ése que sería el primer texto suyo que vería publicado Cortázar y que se inmortalizó en la lectura de todos con el título envidiable de "Casa tomada». De ese jazz sabían quienes lo leían y, desde luego, quienes lo conocieron de cerca o de lejos en el insólito espectáculo de un hombre que no parecía envejecer nunca, como si se quedara a vivir al volante de un automóvil anclado en medio de un embotellamiento infinito en una carretera. De ese jazz sabemos, en fin, quienes apreciamos la delicada minuciosidad con la que tradujo a grandes autores de idiomas que jamás imaginamos aprender y estimamos las cartas personales o los cursos de literatura que son ahora libros complementarios a su obra narrativa; clases y cartas para confirmar, en último término, que la vida se vive mejor leída, leyéndola que es gerundio, leyendo a un escritor tan cercano que en realidad no se ha ido: allí sigue, oteando siempre la mesa de novedades de la librería donde me cito de vez en cuando, sin citarme, con la Maga. Dos metros de estatura inalcanzable, un ojo al gato y otro al garabato, la barba de hippie, las manos más largas del mundo, el cigarro sin filtro equilibrándose en los labios que sonríen y una gabardina que esconde como baúl sin fondo todas las tramas posibles de una novela que se multiplica como saxofón enloquecido y todos los personajes que se desdoblan en cuentos sin cuenta. Miro al estante y -efectivamente-me está esperando Julio Cortázar.

Texto adaptado a partir del artículo «Me espera Cortázar» aparecido en El País el 26/08/2014.

c) Hay marcadores que tienen valores similares. Busca, para los marcadores de la columna de la izquierda, que pertenecen al texto que has leído, un equivalente aproximado en la columna de la derecha. En caso de duda, puede ayudarte el contexto en el que aparece usado el marcador.
1. sin embargo
a) encima
2. además
b) eso sí
3. ahora bien
c) por el contrario
4. en cualquier caso
d) no obstante
5. en cambio
e) primeramente
6. por supuesto
f) desde luego
7. en realidad
g) claro
8. en primer lugar
h) en último término
9. en fin
i) de hecho
10. efectivamente
j) de todos modos 
d) Ahora que ya conoces cuál es la categoría de cada uno de los marcadores de la columna de la izquierda que aparecen en el texto y además les has buscado un equivalente aproximado, es hora de ir un paso más allá. Define cuál es el valor en el texto de cada uno de esos diez marcadores. Tienes el primero hecho como ejemplo.

\begin{tabular}{|l|l|l|}
\multicolumn{1}{|c}{ MARCADOR DISCURSIVO } & VALOR EN EL TEXTO \\
\hline Sin embargo & Refuta lo presentado previamente \\
\hline Además & \\
\hline Ahora bien & \\
\hline En cualquier caso & \\
\hline En cambio & \\
\hline Por supuesto & \\
\hline En realidad & \\
\hline En primer lugar & \\
\hline En fin & \\
\hline Efectivamente & \\
\hline
\end{tabular}

e) En el texto que hemos leído aparecen referencias a seis cuentos o libros de cuentos de Julio Cortázar cuyos títulos tienes a continuación. ¿Sabrías relacionar cada cuento o libro de cuentos con el fragmento del artículo en el que se habla de él?

\section{1) "Casa tomada» \\ 2) «Cartas a una señorita en París» \\ 3) «Cartas de mamá»}

\section{4) Historias de cronopios y de famas \\ 5) «Continuidad de los parques» \\ 6) «La autopista del sur»}

a) «la cronometría de cronopio»

b) «[...] hay señoritas en París capaces de provocar un raro sortilegio por el que cualquiera puede de pronto escupir pequeños conejitos por la boca.» 
c) «[...] hay madres que nos siguen escribiendo cartas con las últimas novedades de todo lo que pasa en casa, entregadas puntualmente en el buzón del departamento que hemos alquilado en un país lejano, sin importar que mamá en realidad ya murió.»

d) «[...] como en cada trama de sus cuentos donde los personajes son el lector que lee los párrafos donde él mismo se aproxima al sillón de terciopelo verde donde las palabras son el espejo de un hombre que se aproxima al sillón de terciopelo verde para cumplir una venganza perfecta.»

e) «[...] ése que sería el primer texto suyo que vería publicado Cortázar y que se inmortalizó en la lectura de todos con el título envidiable de "Casa tomada".»

f) «[...] como si se quedara a vivir al volante de un automóvil anclado en medio de un embotellamiento infinito en una carretera.» 
Actividad 2:

\section{Márcate un cuento}

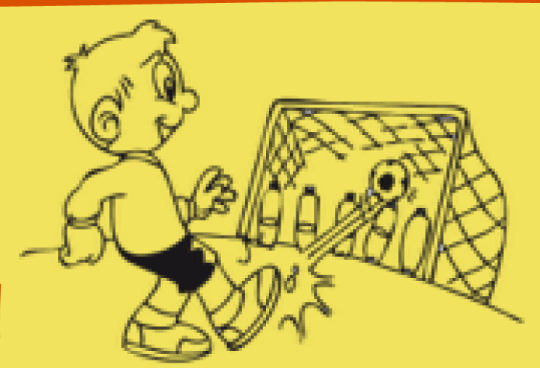

¿Recuerdas los cinco cuentos de Cortázar que han aparecido en la actividad anterior? A continuación tienes un fragmento de cada uno de ellos, pero, para que los textos tengan sentido, falta un marcador. En cada caso, elige la opción correcta de entre las propuestas. La clasificación de los marcadores que has hecho en la actividad 1 puede serte de ayuda.
a) de ahí
c) por el contrario
b) además
d) antes bien

1. El sonido venía impreciso y sordo, como un volcarse de silla sobre la alfombra o un ahogado susurro de conversación. También lo oí, al mismo tiempo o un segundo después, en el fondo del pasillo que traía desde aquellas piezas hasta la puerta. Me tiré contra la pared antes de que fuera demasiado tarde, la cerré de golpe apoyando el cuerpo; felizmente la llave estaba puesta de nuestro lado y corrí el gran cerrojo para más seguridad.

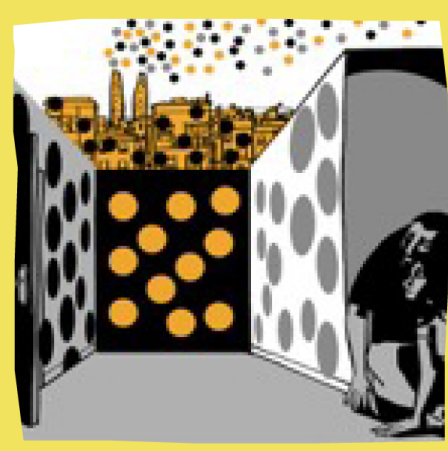

«Casa tomada», en Bestiario (1951)
a) encima
c) con todo
b) en otros términos
d) pues bien

2. No era tan terrible vomitar conejitos una vez que se había entrado en el ciclo invariable, en el método. [...] Me decidí,

matar el conejito apenas naciera. Yo viviría cuatro meses en su casa: cuatro -quizá, con suerte, tres- cucharadas de alcohol en el hocico. (¿Sabe usted que la misericordia permite matar instantáneamente a un conejito dándole a beber una cucharada de alcohol? Su carne sabe luego mejor, dicen, aunque yo... Tres o cuatro cucharadas de alcohol, luego el cuarto de baño o un piquete sumándose a los desechos.)

«Cartas a una señorita en París», en Bestiario (1951)

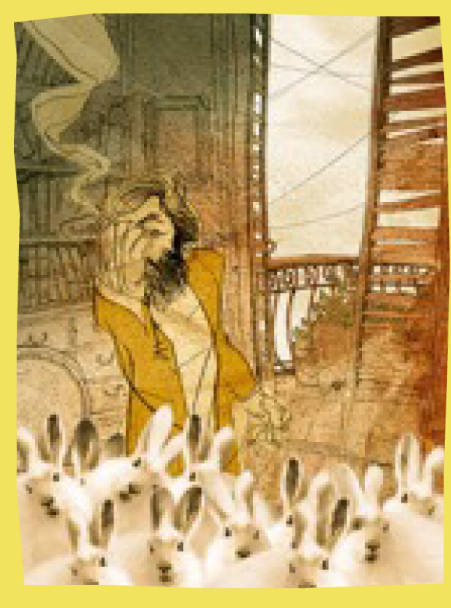




$\begin{array}{ll}\text { a) entre paréntesis } & \text { c) o sea } \\ \text { b) no obstante } & \text { d) en realidad }\end{array}$

3. Puesto a buscar semejanzas, por gusto de aliarse a la imbecilidad, dos de los hombres que pasaban cerca debían ser argentinos por el corte de pelo, los sacos, el aire de suficiencia disimulando el azoramiento de entrar en París. Uno sobre todo se parecía a Nico, puesto a buscar semejanzas. El otro no, y éste tampoco apenas se le miraba el cuello mucho más grueso y la cintura más ancha.

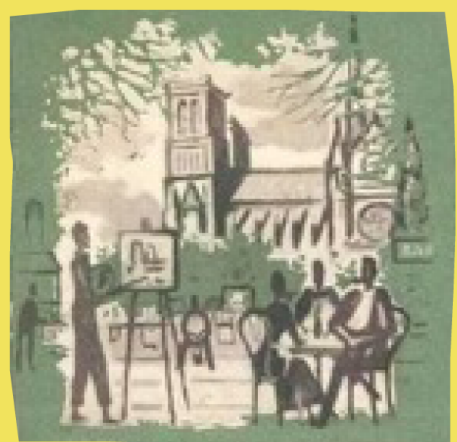

"Cartas de mamá», en Las armas secretas (1959)
a) en cambio
c) aparte
b) por un lado
d) en el fondo

4. Los famas para conservar sus recuerdos proceden a embalsamarlos en la siguiente forma: Luego de fijado el recuerdo con pelos y señales, lo envuelven de pies a cabeza en una sábana negra y lo colocan parado contra la pared de la sala, con un cartelito que dice: «Excursión a Quilmes», o: «Frank Sinatra».

Los cronopios, esos seres desordenados y tibios, dejan los recuerdos sueltos por la casa, entre alegres gritos, y ellos andan por el medio y cuando pasa corriendo uno, lo acarician con suavidad y le dicen: "No vayas a lastimarte», y también: «Cuidado con los escalones.» Es por eso que las casas de los famas son ordenadas y silenciosas, mientras en las de los cronopios hay gran bulla y puertas que golpean. Los vecinos se quejan siempre de los cronopios, y los famas mueven la cabeza comprensivamente y van a ver si las etiquetas están todas en su

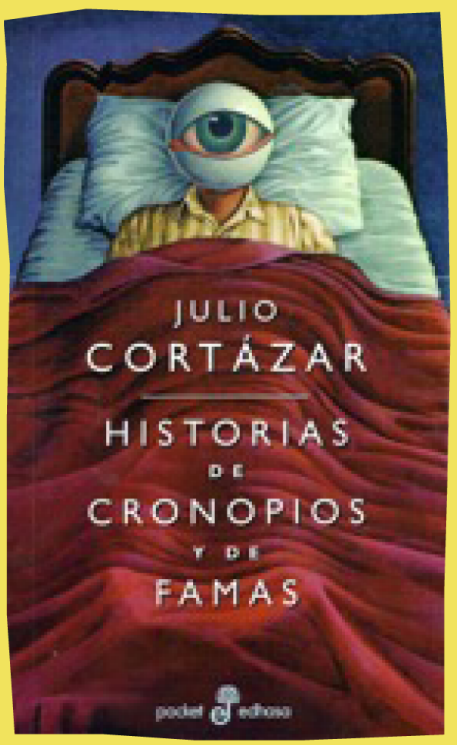
sitio.

"Conservación de los recuerdos", en Historias de cronopios y de famas (1962) 

a) por consiguiente
c) no obstante
b) primero
d) aparte

5. Palabra a palabra, absorbido por la sórdida disyuntiva de los héroes, dejándose ir hacia las imágenes que se concertaban y adquirían color y movimiento, fue testigo del último encuentro en la cabaña del monte. entraba la mujer, recelosa; ahora llegaba el amante, lastimada la cara por el chicotazo de una rama. «Continuidad de los parques», en Final del juego (1964)

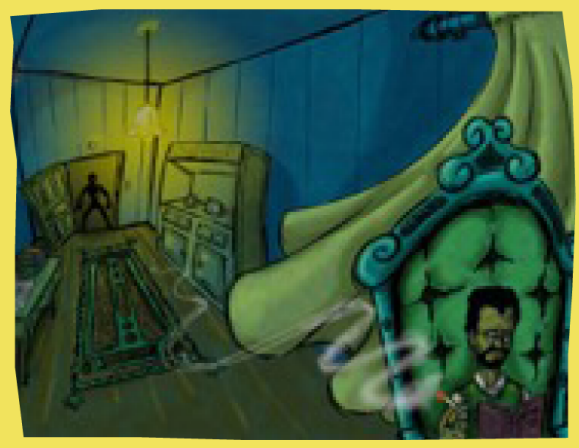
a) por tanto
c) mejor dicho
b) además
d) $\sin$ embargo

6. Otra vez volvía a faltar el agua, y Taunus envió a tres de sus hombres, entre ellos el ingeniero, para que trataran de establecer contacto con los lugareños. Sin que pudiera saberse por qué, la resistencia exterior era total; bastaba salir del límite de la autopista para que desde cualquier sitio Ilovieran piedras. En plena noche alguien tiró una guadaña que golpeó el techo del DKW y cayó al lado del Dauphine. El viajante se puso muy pálido y no se movió de su auto, pero el americano del De Soto (que no formaba parte del grupo de Taunus pero que todos apreciaban por su buen humor y sus risotadas) vino a la carrera y después de revolear la guadaña la devolvió campo afuera con todas sus fuerzas, maldiciendo a gritos. , Taunus no creía que conviniera ahondar la hostilidad; quizás fuese todavía posible hacer una salida en busca de agua.
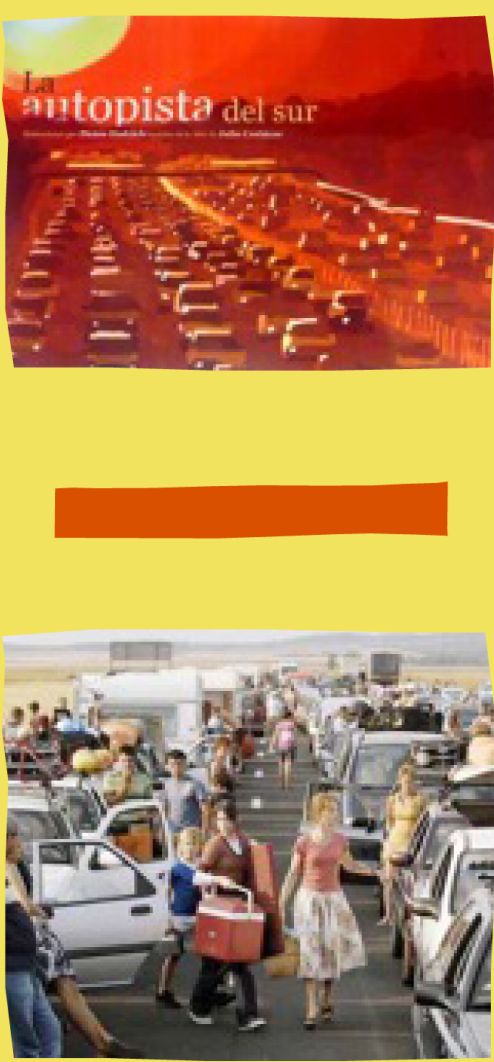
«La autopista del sur», en Todos los fuegos el fuego (1966) 


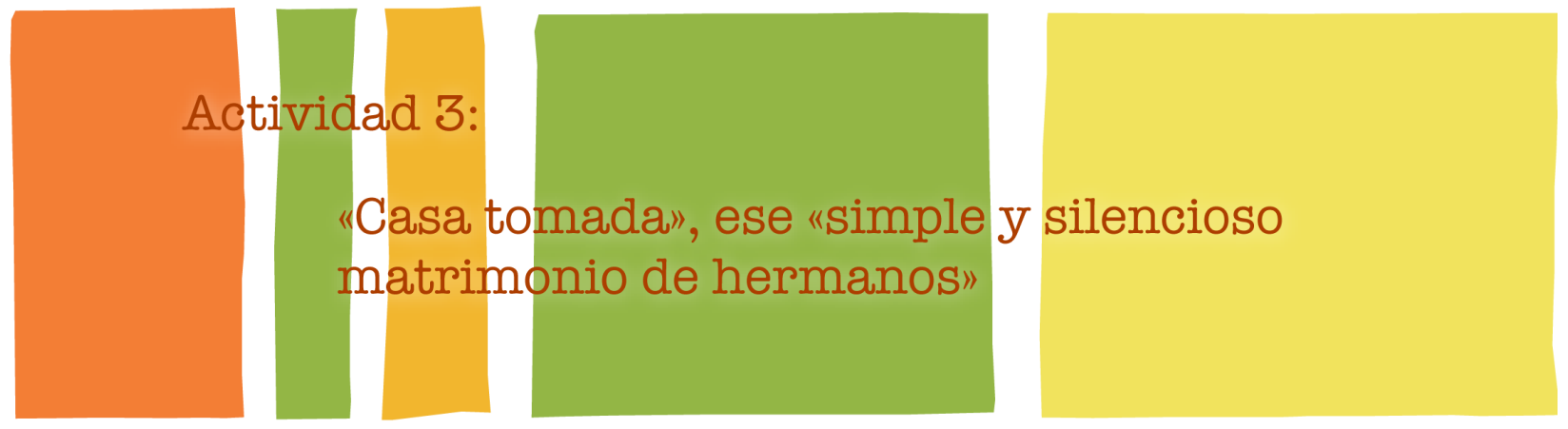

«Casa tomada» fue el primer cuento de Cortázar en ser publicado. Fue en 1947, en una revista de la que era entonces editor Jorge Luis Borges. Posteriormente aparecería recogido en Bestiario (1951). La acción del cuento se sitúa en la Argentina y, aunque desconocemos la fecha precisa de los acontecimientos, estos han de darse con posterioridad a 1939. «Casa tomada» relata la historia de dos hermanos (Irene y el narrador, cuyo nombre no sabemos), que han vivido siempre juntos en una antigua y enorme casa colonial que durante generaciones ha pertenecido a su familia. De hecho, parece en cierto modo como si cuidar de la casa se hubiera convertido en el cometido esencial de sus vidas, hasta el punto de que, inexplicablemente, ninguno de los dos se
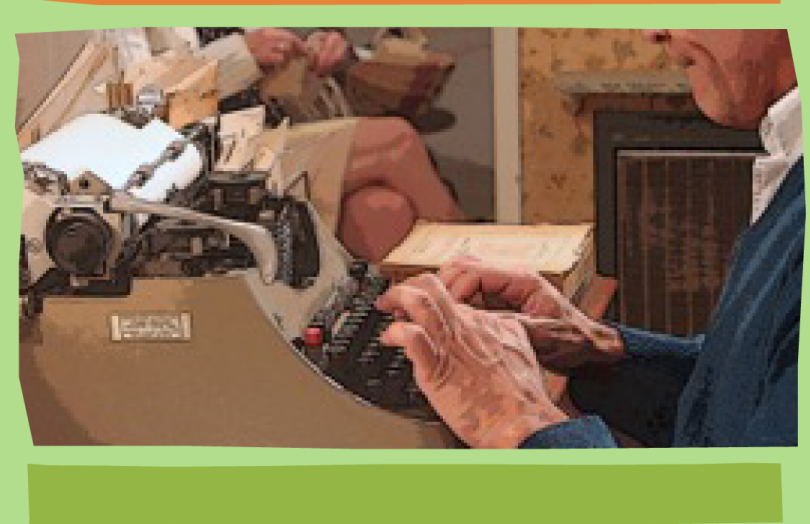

ha casado, aunque ambos han pasado ya de los cuarenta. El narrador describe con detalle la casa y relata las pequeñas rutinas de cada día. De pronto, sin embargo, unos extraños ruidos (susurros, el volcar de una silla) rompen la cotidianeidad y los hermanos se ven impelidos a ir abandonando partes de la casa que parecen tomadas por intrusos. Finalmente estos se harán con toda la casa y los hermanos huirán una noche tirando la llave de la puerta principal a una alcantarilla para evitar que a algún desafortunado ladrón le dé por entrar y se encuentre, a esas horas, con la casa tomada.

a) En este cuento de Cortázar, la casa cobra un protagonismo que pocas veces la literatura concede a los espacios. Vamos, pues, a conocer ese lugar un poco mejor. Para ello, utiliza los marcadores incluso o además para relacionar los enunciados siguientes. Tienes un ejemplo de cada tipo para servirte de ayuda. 


\section{iRecuerda!}

- La diferencia entre incluso y además es que este último añade en el segundo miembro una información que de ningún modo podía desprenderse del primero, mientras que incluso desarrolla o completa una información intrínsecamente relacionada con lo contenido en el primer miembro.

\section{Ejemplos:}

\section{Es una casa rica / Es lujosa:}

Es una casa rica, incluso lujosa.

Es una casa luminosa / Cuenta con muchas estancias:

Es una casa luminosa y además cuenta con muchas estancias.

1. Es una casa sin demasiada decoración / Es una casa austera

2. Tiene muchas habitaciones / Algunas habitaciones están vacías

3. Está muy limpia / Está resplandeciente

4. Tiene una cocina amplísima / Tiene una cocina bien amueblada

5. Es una casa tranquila / Es silenciosa

6. Es una casa heredada / Está en el centro de Buenos Aires

7. Es una casa agradable / Es acogedora

8. Tiene amplios ventanales / Tiene muebles preciosos

b) Ahora que ya conocemos la casa, vamos a imaginar cómo sería el día a día de Irene y su hermano en ella. Hemos pensado en frases que pudieran formar parte de sus conversaciones cotidianas, pero hace falta que tú las completes uniendo, mediante así que o entonces, los dos enunciados que se dan en cada caso. Tienes hechas las dos primeras a modo de ejemplo.

\footnotetext{
$\frac{11-}{6}-$ iRecuerda!

$\Rightarrow$ Así que y entonces introducen una consecuencia, pero mientras que entonces requiere de un diálogo entre dos voces, así que funciona con una sola.
} 


\section{Ejemplos:}

Dices que quieres acostarte pronto / Deja ya de trabajar:

Dices que quieres acostarte pronto. Entonces, deja ya de trabajar.

Hoy he comprado un nuevo libro interesantísimo / Empezaré a leerlo de inmediato:

Hoy he comprado un nuevo libro interesantísimo, así que empezaré a leerlo de inmediato.

1. Dices que quieres acabar de tejer el suéter antes de acostarte / Empieza ya

2. He oído ruidos / Nos quedaremos de esta parte de la casa

3. Dices que ya has acabado de leer el libro / Prepara la cena

4. Dices que ya no tienes más lana / Tendrás que dejar de tejer

5. Dices que ya no queda nada más por limpiar / Descansemos

6. Salí corriendo / Tengo solo lo puesto.

7. Se me quedó la lana del otro lado / Ya no podré tejer más

8. Un ladrón puede querer entrar en la casa / Tiraré la llave por la alcantarilla

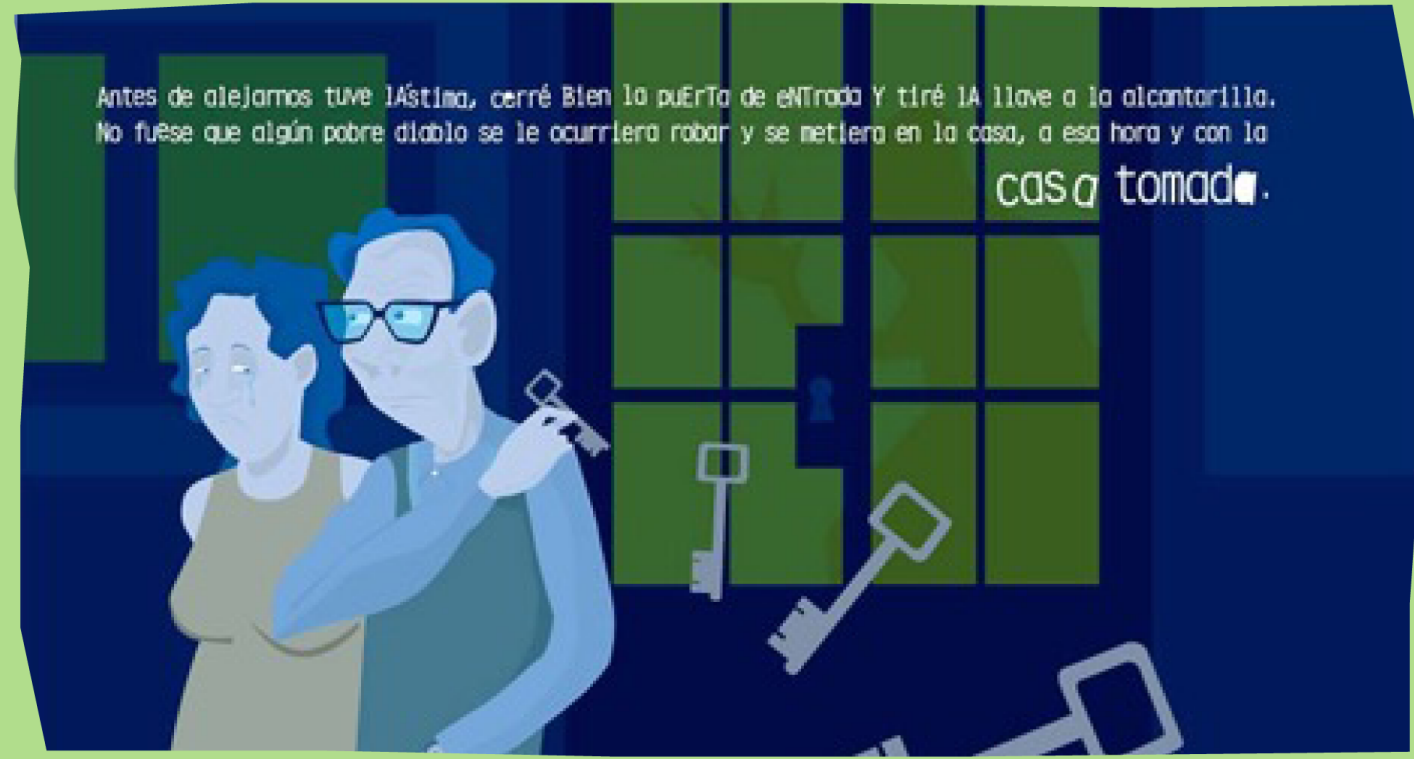


Actividad 4:

\section{Medio siglo de RAYUELA}

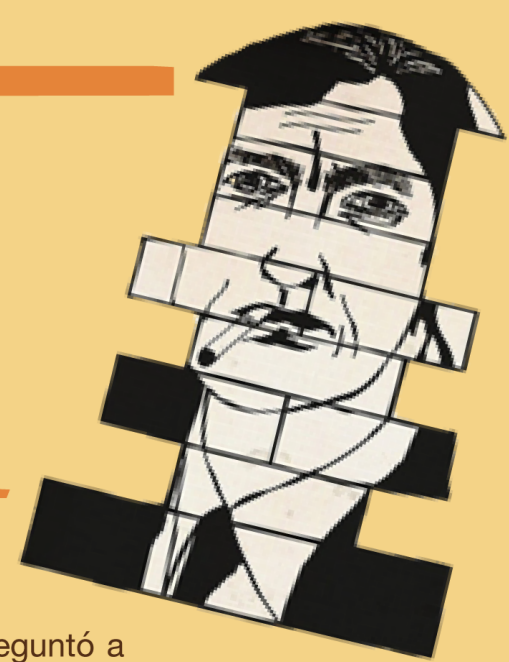

En 2013 se cumplieron cincuenta años de la publicación de Rayuela. Con motivo de esta efeméride, el diario El País les preguntó a distintos escritores en lengua española, pertenecientes a diversas generaciones, cuál era su parecer sobre esta novela insólita. Sus puntos de vista fueron muy diferentes. A continuación, recogemos un extracto de varias de estas opiniones, pero hemos eliminado algunos marcadores del texto, de modo que, para que este tenga sentido, deberás ponerlos en el lugar correspondiente. A veces, más de una solución es posible.

\begin{tabular}{|lll|}
\hline por ejemplo & de hecho & pues \\
en cambio (2) & eso sí & en fin \\
en realidad & sin duda & desde luego \\
sin embargo & más aún & a fin de cuentas
\end{tabular}

«¿Encontraría a la Maga...?». de los libros inolvidables uno aprende de memoria al menos el primer párrafo, o esa lectura nunca existió, se la llevó el agua del tiempo en su fluir incesante. Y la entrada de Rayuela puede leerse ya, pasado medio siglo, como la de cualquier otro de los clásicos que vuelven siempre a la memoria envueltos en su propio resplandor como sucede, , con el arranque de Anna Karénina, La metamorfosis o Cien años de soledad.

Para los nostálgicos que aprendimos en las páginas de Rayuela a despreciar el orden establecido y a cuidarnos de la transgresión de escribir en papel rayado y apretar el tubo de pasta dentífrica desde abajo, cabe una pregunta: ¿habrá envejecido Rayuela junto con todos nosotros? Es una pregunta generacional y hay que tomarla así.

He indagado entre los escritores jóvenes que se abren camino en este siglo XXI de tan pocas certezas y demasiadas incertidumbres, si reconocen en ella su atrevido sentido de ruptura, la narración siempre al borde del abismo, al lector que atraviesa la cuerda floja en persecución del novelista que va por delante balanceando la pértiga en busca de una alternancia perturbadora entre lo cómico y lo trágico. 
Algunos coinciden plenamente conmigo, otros, me han dicho que lo que pasa es que Rayuela fue a mi generación lo que Los detectives salvajes de Bolaño es a las nuevas, una Biblia laica de enseñanzas acerca de cómo romper todos los platos de la alacena con el mayor escándalo posible, pero se trata de dos generaciones distintas. Veamos, , qué opinan los más jóvenes.

Un juguete sofisticado. A Agustín Fernández Mallo (A Coruña, 1967) le faltaban cuatro años para nacer cuando se publicó Rayuela. No la ha vuelto a leer entera desde la primera vez. , de cuando en cuando hace «catas selectivas». Su conclusión es que funciona muy bien a trozos, que tienen una entidad poética al margen de la narrativa. En su opinión, la novela de Julio Cortázar «abrió una vía al experimentalismo y al uso de la cultura popular sin tapujos, sin esa condescendencia que se usa para quedar bien. En Cortázar era algo vivido, real, no un artefacto montado ad hoc. Su influencia la admite la mayoría de los escritores españoles de mi generación».

Mercedes Cebrián (Madrid, 1971) tampoco la ha vuelto a leer desde que lo hizo a los 17 años, y por eso insiste en que, sus comentarios se refieren a aquella primera impresión. Ahora, dice, está curada de espanto, «vieja» (¿), no querría parecer naïve. ¿Y a los 17 ? «Rayuela es una novela de formación esencial para un escritor en lengua castellana. Aprendes de todo, carpintería, bricolaje. Enseña también que la literatura no es solo seriedad, que puede ser un juego, que en una novela cabe lo que tú quieras. Me da pena pensar que ya no la podría releer con la ilusión del descubrimiento. También es un juguete sofisticado muy útil para bajarles los humos a los descubridores permanentes de artefactos que piensan que lo último de lo último es decirle a alguien, en la página 10 , "pase a la página 48 "».

Contra Rayuela. Desde la Argentina, Damián Tabarovsky (Buenos Aires, 1967) rompe contundentemente la devoción cortaziana: «¿En qué momento Rayuela se convirtió en un libro leído en la adolescencia y nunca jamás en la adultez? O , ¿en qué momento pasó a ser un texto adolescente? No lo sé. Sé, , que para mí, y para muchos de mi generación, Cortázar significa esa época de la vida en que nos pasan cosas vergonzantes: decir que nos gustaba Cortázar es una de esas. , a mí nunca me pasó, pero sí me ocurrió con Roberto Fontanarrosa, que vendría a ser lo mismo, pero peor».

En 1962, en una carta, Julio Cortázar escribió: «Nadie es clásico si no quiere. Los profesores pueden pegarle la etiqueta, pero él (y sus libros) le escupen encima. Yo soy siempre el mismo desconcertado cronopio que anda mirando las babas del diablo en el aire, y que recién a los veinte mil kilómetros descubre que no ha soltado el freno de mano». 
Cortázar, , nunca envejeció, ni tampoco dejó de crecer, como no ha dejado de crecer Rayuela, un libro de iniciación que, igual que su autor, seguirá botando años por el camino. Solo hay que leerlo, o volver a leerlo empezando, , por el primer capítulo. Allí comienza su eternidad.

Texto adaptado a partir del artículo «Rayuela, ¿cursi o clásico?», publicado en El País el 28/06/2013, y del reportaje «Rayuela, sigue el juego» aparecido en el mismo diario el 29/06/2013.

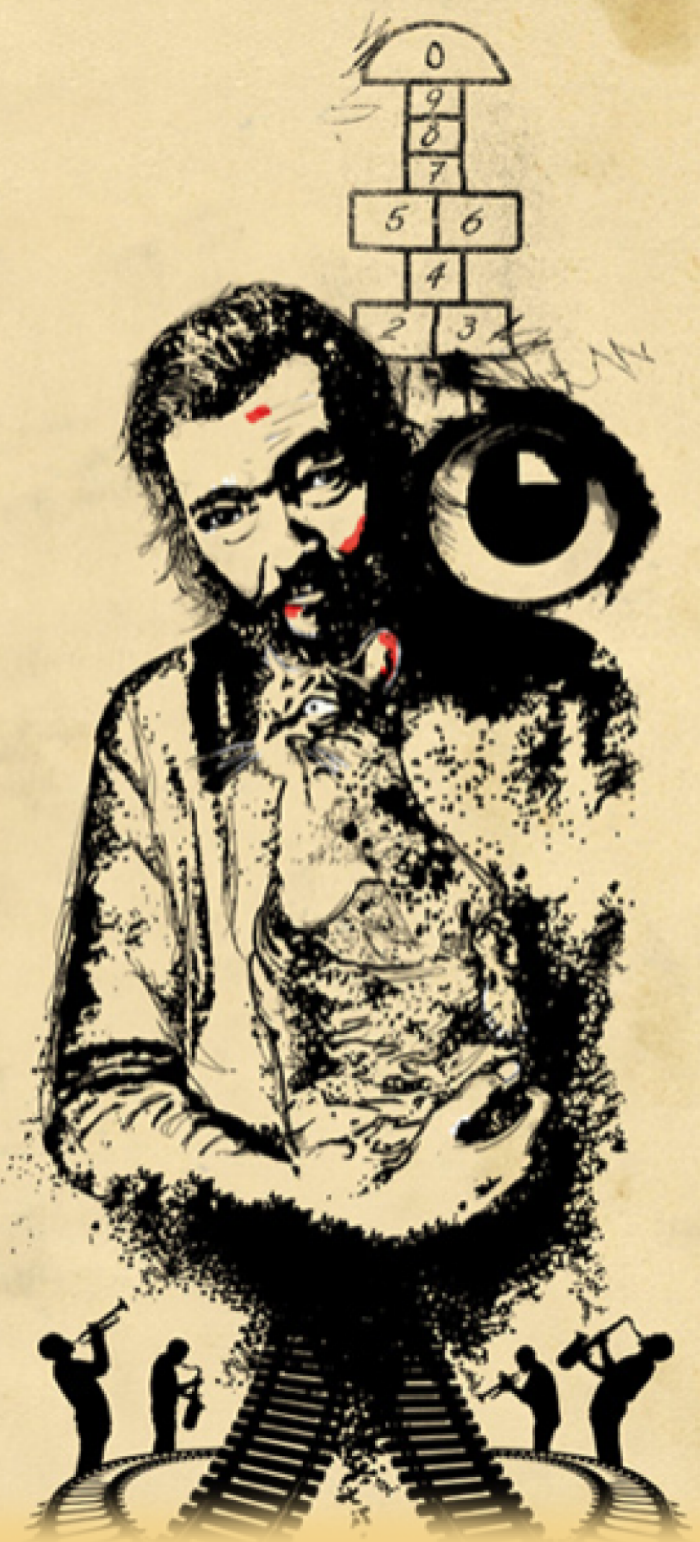




\section{Actividad 5:}

\section{La Maga y Oliveira}

En esta actividad vamos a conocer mejor a Horacio Oliveira y la Maga, los dos protagonistas de Rayuela.

a) Para saber más de Horacio Oliveira, elige en cada caso la opción adecuada.

Tienes la primera oración hecha como ejemplo.

\section{iRecuerda!}

- Eso sí es un conector contraargumentativo que introduce un miembro discursivo que atenúa o invierte las conclusiones que se pueden inferir del miembro precedente.

\section{Horacio Oliveira...}

... y la Maga discuten a menudo, eso sí,...
a) ... siempre se reconcilian.
b) ... nunca se reconcilian.

1) ... no suele expresar abiertamente sus sentimientos, eso sí, ...

a) ... ama a la Maga

b) ... quiere poco a la Maga.

2) ... vive en un apartamento húmedo e insalubre, eso sí, ...

a) ... en una ciudad fría.

b) ... en París.

3) ... sabía que el bebé de la Maga estaba muerto, eso sí, ...

a) ... no se lo dijo a su madre.

b) ... se lo dijo a su madre. 
b) Para conocer mejor a la Maga, relaciona los elementos de las dos columnas a través del marcador antes bien. En total, tendrás que escribir siete frases que caractericen a la protagonista femenina de Rayuela, aunque la primera ya está dada como ejemplo.

irecuerda!

$\Rightarrow$ Antes bien es un conector contraargumentativo que comenta el mismo tópico que el miembro anterior, de tal manera que el nuevo miembro sustituye la afirmación que es negada en el primero.

\section{La Maga...}

1) ... no es rica, ...

2) ... no es muy espabilada, ...

3) ... no es culta, ...

4) ... no es poco agraciada, ...

5) ... no tiene don de palabra, ...

6) .... no es arisca, ...

7) ... no es observadora, ... a) ... es muy cariñosa.

b) ... apenas ha estudiado

c) ... es muy atractiva.

$\ldots$, antes bien, ...

d) ... a veces le cuesta expresarse.

e) ... es bastante distraída.

f) ... es bastante pobre.

g) ... es bastante ingenua.

\section{Ejemplo:}

La Maga no es rica, antes bien, es bastante pobre. 


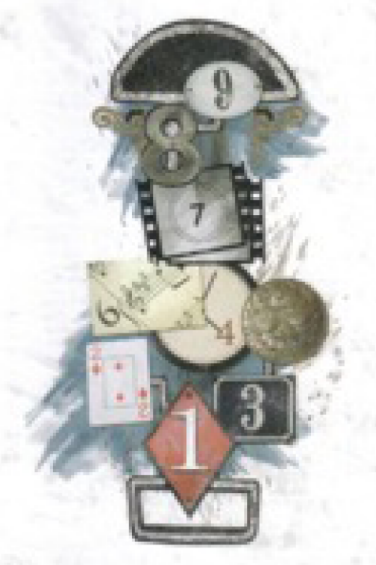

\section{Actividad 6:}

\section{Una rayuela de cuento}

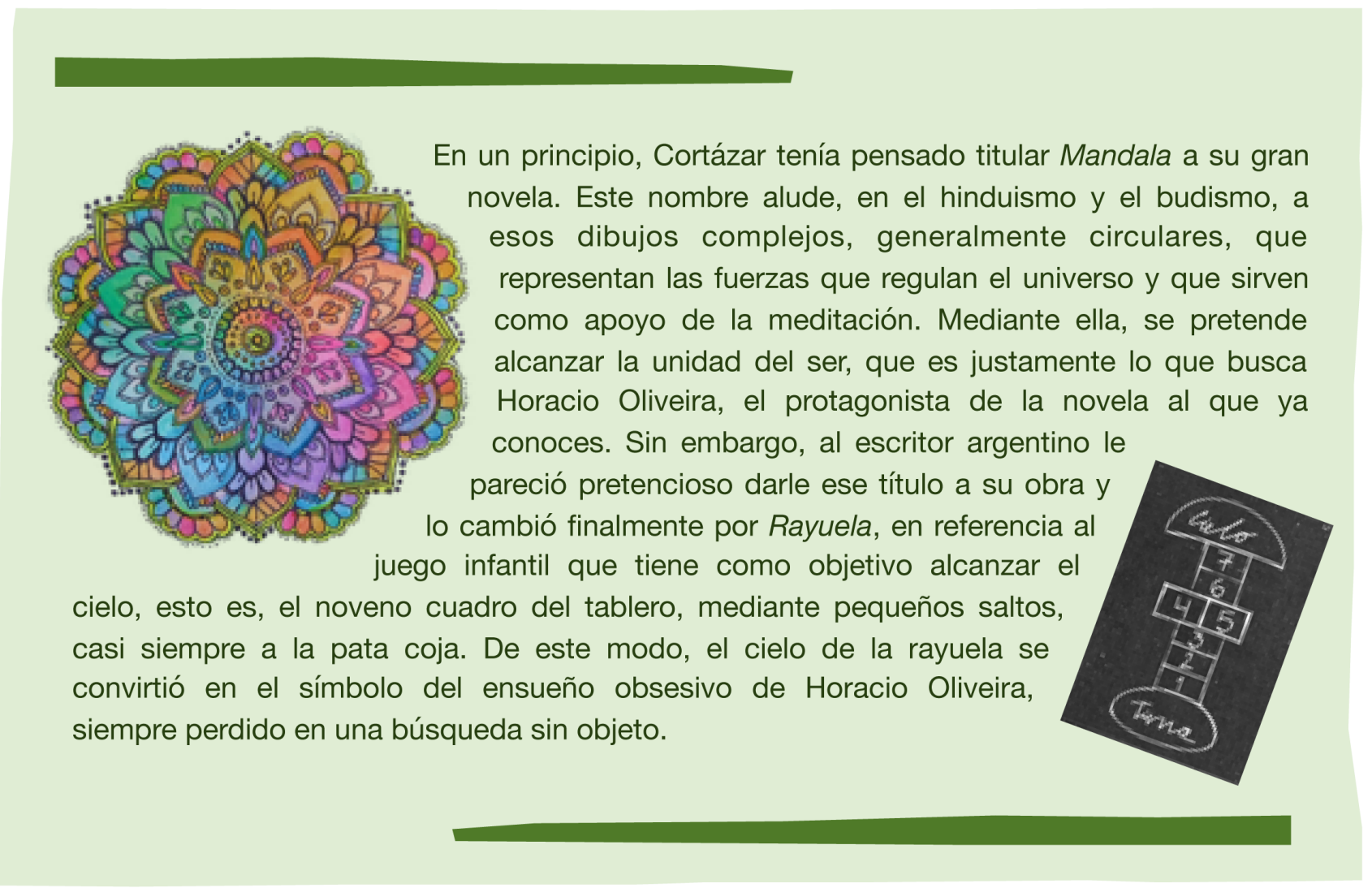

Seguro que alguna vez has jugado a la rayuela. Pues bien, hoy vas a hacerlo de nuevo. He aquí una rayuela en cada una de cuyas casillas está el comienzo de uno de los ocho párrafos de "Simulacros", un cuento de Cortázar incluido en Historias de cronopios y de famas. Tu objetivo es llegar al cielo, para lo cual tendrás que componer un pequeño relato o cuento utilizando el mayor número posible de cuadros de la rayuela. Habrás de emplear un mínimo de cuatro pero, ya sabes, cuantas más casillas utilices, más cerca estarás del cielo. Para dar coherencia a tu historia sírvete de los marcadores del discurso que hemos estudiado en esta unidad. También en este caso tendrán que aparecer un mínimo de cuatro, pero cuantos más uses, mejor. La extensión aproximada del cuento serán 300-500 palabras. 


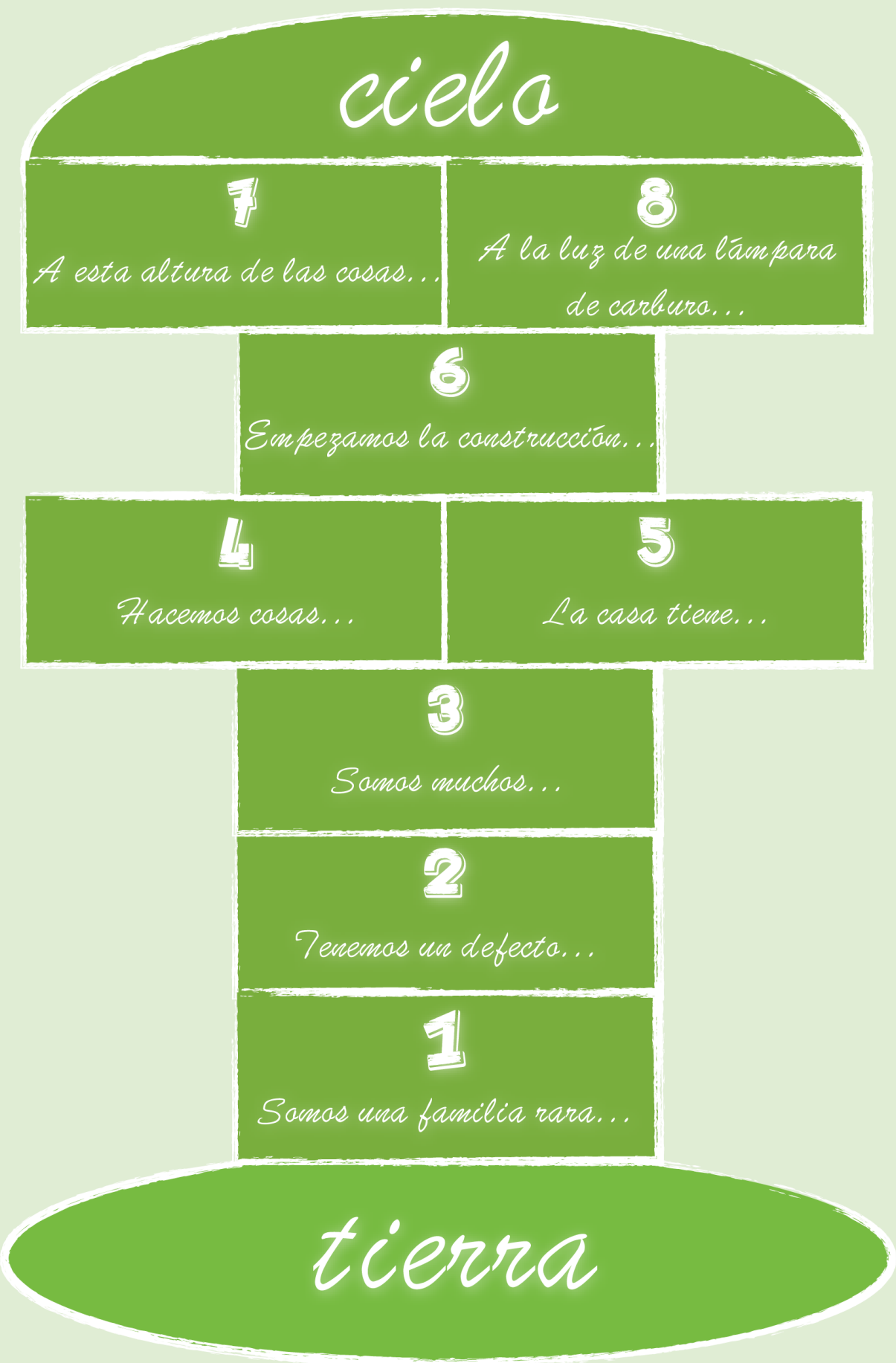

